\title{
Achieving Effective and Efficient Basal Insulin Optimal Management by Using Mobile Health Application (APP) for Type 2 Diabetes Patients in China
}

This article was published in the following Dove Press journal: Diabetes, Metabolic Syndrome and Obesity: Targets and Therapy

\author{
Xiaoling Cai (D) \\ Fang Zhang' \\ Chu Lin $\mathbb{D}^{1}$ \\ Xiaomei Zhang ${ }^{2}$ \\ Zhufeng Wang ${ }^{3}$ \\ Huifang Xing ${ }^{4}$ \\ Lin $\mathrm{Nie}^{5}$ \\ Xueyao $\mathrm{Han}^{\prime}$ \\ Linong $\mathrm{Ji}^{1}$
}

'Department of Endocrinology and Metabolism, Peking University People's Hospital, Beijing, People's Republic of China; ${ }^{2}$ Department of Endocrinology and Metabolism, Peking University International Hospital, Beijing, People's Republic of China; ${ }^{3}$ Department of Endocrinology and Metabolism, Guanganmen Traditional Medicine Hospital, Beijing, People's Republic of China; ${ }^{4}$ Department of Endocrinology and Metabolism, Beijing Mentougou Hospital, Beijing, People's Republic of China; ${ }^{5}$ Department of Endocrinology and Metabolism, Beijing Airport Hospital, Beijing, People's Republic of China
Correspondence: Linong Ji

Email prof_jilinong@aliyun.com

\begin{abstract}
Aim: To evaluate the effectiveness of the mobile health application (APP) education in basal insulin optimal management program for insulin-naive type 2 diabetes (T2D) patients in China. Methods: The basal insulin optimal management program was launched in 297 hospitals in China, throughout the six main regions of China. A total of 17,208 insulin-naive patients with T2D who started to use basal insulin were screened. The mobile health APP was downloaded in each recruited patient's mobile phone and the doctor's mobile phone. Then, according to the instructions and education materials in the APP, these patients began their self-management of insulin dosage titrations and contacted their doctors by APP if they need help.
\end{abstract}

Results: Overall, 12,530 patients with T2D were finally included in the analysis. The average age was $51.97 \pm 12.76$ years, and $58 \%$ of them were males. The average body mass index is $24.46 \pm 3.83 \mathrm{~kg} / \mathrm{m}^{2}$, and the average HbAlc at baseline was $8.33 \pm 2.11 \%$ with $24 \%$ of the subjects reaching the target of $\mathrm{HbAl} c<7.0 \%$ at baseline. After 3 months of treatment and educations through the APP, HbA1c decreased significantly from baseline $(-1.02 \pm 1.72 \%)$, with $59 \%$ of the patients reaching $\mathrm{HbA} 1 \mathrm{c}<7.0 \%$. After 6 months, the glycemic control of HbA1c also decreased from baseline significantly $(-1.01 \pm 1.67 \%)$. Dosage of insulin daily was $0.23 \pm 0.09 \mathrm{IU} / \mathrm{kg}$ at baseline, and $0.23 \pm 0.23 \mathrm{IU} / \mathrm{kg}$ after 6 months of treatment. Regarding the profiles of hypoglycemia treatment, 3145 patients received basal insulin in combination with mono oral anti-diabetic drug (OAD), 1204 patients with dual OADs, 208 patients with triple OADs, and 17 patients with quarter OADs.

Conclusion: Patients could benefit from the basal insulin optimal management program in self-management by using mobile health APP educations. For T2D patients who are going to start insulin treatment, mobile health APP can help them to reach the target of glycemic control with appropriate dosage of insulin.

Keywords: basal insulin, HbAlc, insulin-naive, type 2 diabetes

\section{Introduction}

Type 2 diabetes (T2D) is a complex disease with an increasing prevalence worldwide. According to the International Diabetes Federation, it was estimated that in 2015 there were 415 million people with diabetes aged 20-79 years, and this figure was predicted to rise to 642 million by $2040 .{ }^{1}$ In China, the estimated overall prevalence of diabetes was $10.9 \%$ in 2013 and this figure will be $11.6 \%$ in 2045 by prospective estimation. $^{1-3}$

With respect to clinical practice for $\mathrm{T} 2 \mathrm{D}$, lifestyle interventions as diet and exercise, diabetic education, blood glucose monitoring, and medicine taking are 
required. However, due to the large population of diabetes in China, traditional face-to-face visit cannot meet the need of diabetic management well. Moreover, the increase of health-care expenditures urged the necessity of developing cost-effective tools for diabetes education and selfmanagement.

The mobile health management may be a promising tool to facilitate the management of diabetes and provide more accessible diabetes education. Recently many studies indicated that mobile medical intervention tools are effective in a wide range of areas for both disease management and lifestyle changes. ${ }^{4-8}$ Some studies have shown that among diverse computer-based technologies, mobile phone interventions for diabetes self-management can significantly reduce hemoglobin A1c (HbA1c) levels. ${ }^{9,10}$

In treatment with $\mathrm{T} 2 \mathrm{D}$, as recommended by the Chinese Guideline for Diabetes Prevention and Treatment and from the American Diabetes Association (ADA) guideline, insulin therapy is one of the best choices for T2D patients who could not get well glucose control by at least one oral antidiabetic drug (OAD). Moreover, according to the recommendations, for insulin-naive patients, basal insulin therapy, is one of the best choices for starting insulin treatment. However, previous studies from China showed that in patients with T2D, basal insulin treatment in combination with OADs could not optimize the glycemic control as expected. In the ORBIT study, the HbA1c level for initiating basal insulin treatment in Chinese T2D patients was 9.6 $\pm 2.0 \%$, with $55.1 \%$ of these patients initiating insulin treatment when their $\mathrm{HbAlc}$ levels were higher than 9\%. Moreover, in more than $40 \%$ of these patients, the insulin dosage did not change during the first 3 months of basal insulin treatment. ${ }^{11-13}$

Therefore, we carried out this program, by using the mobile health application (APP) in basal insulin optimal management program for insulin-naive T2D patients in China, the effectiveness of this kind of education in telemedicine was to be evaluated.

\section{Methods}

\section{Study Design and Inclusion Criteria}

This study is a multicenter, observational, basal insulin optimization education program. The primary aim of this education program was to investigate the effectiveness of education by using mobile health APP in basal insulin optimal management in insulin-naive T2D patients in China. The inclusion criteria for this program were as follows: (1) patient with T2D; (2) patient with the age $\geq 18$ years; (3) patient not well controlled by oral hypoglycemic agents and need to start basal insulin treatment; (4) patient whose $\mathrm{HbAlc}$ was more than $7 \%$. The exclusion criteria included: (1) patent with type 1 diabetes mellitus; (2) patient with mental illness; (3) patient who was going to start with other insulin strategies but not basal insulin alone; (4) nursing mothers or pregnant woman.

The protocol of this program was approved by the Ethical Committee of Peking University International Hospital. All the patients were provided with the informed consent. The patients were recruited from 297 hospitals throughout 152 cities in China from May 2017 to December 2017. Totally 17,208 patients were screened and 12,530 eligible patients were included finally.

\section{Study Procedure}

All the eligible patients initiated basal insulin therapy in combination with previous OADs. Dosage of basal insulin for initiate and the titration strategy were according to the recommendation of China diabetes guideline.

On visit 1, after the patients signed the informed consent, a software about self-management including diet and exercise, blood glucose monitoring, smoking cessation, weight control, hypoglycemia, dosage titration for basal insulin, etc. was installed in the patient's smartphone. All patients were taught about how to begin insulin injection by themselves and about what to do in case of hypoglycemia, delivered by diabetes education nurses showing patients the function of a panel computer. Patients needed to attend an hour of education session on the first day at the hospital, and educated nurses explain to patients.

These patients were required to return to the same physician for the follow-up visits at 3 and 6 months for visit 2 and visit 3. If the patient was lost to follow-up, a structured telephone interview would be performed by the investigator to realize the patient's condition.

At baseline and the follow-up period, the following information should be collected from each patient: 1) demographics including age, gender, residential region, as central, southeast, southwest, northwest, northeast and south; 2) diabetic and family histories; 3) physical examinations including height, body weight, sitting blood pressure; 4) and laboratory tests including $\mathrm{HbAlc}$, fasting and postprandial blood glucose level; 5) adverse events. Specific information about the hypoglycemic treatments were identified, including use of OADs. The flowchart is shown in Figure 1. 


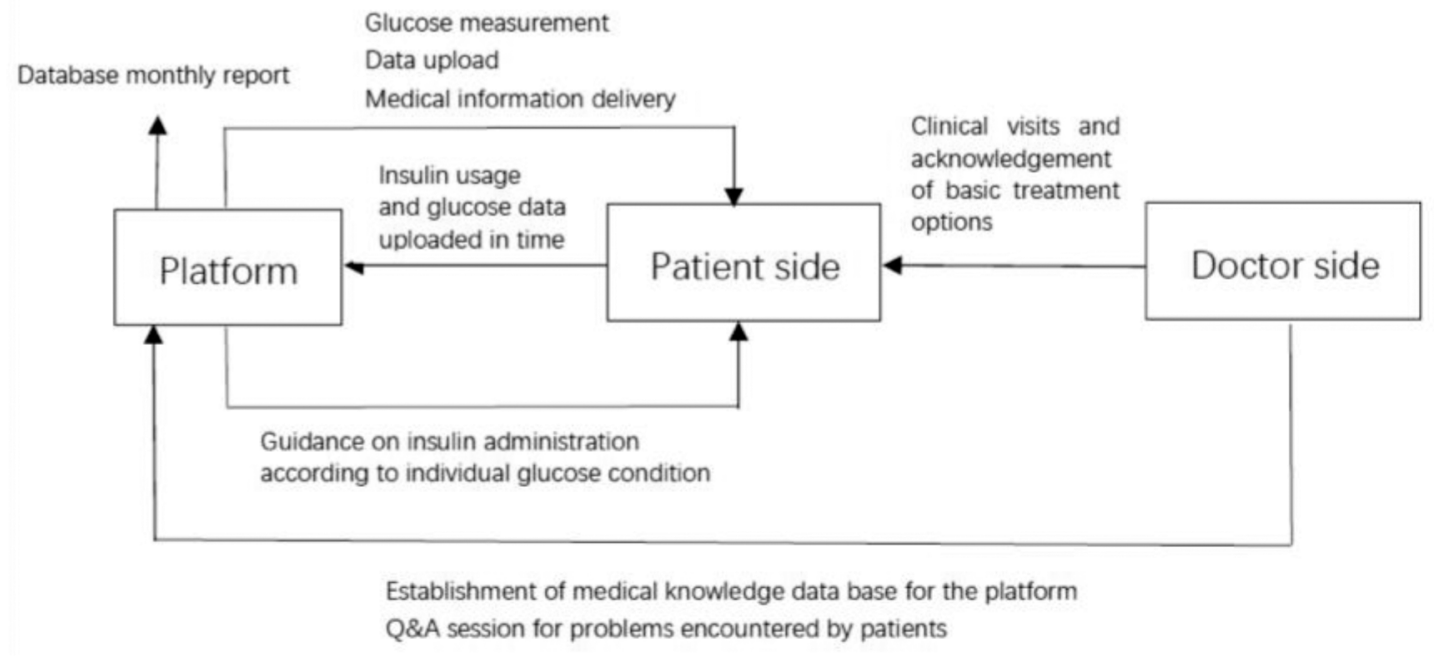

Figure I Flowchart of this program.

\section{Laboratory Methods}

All laboratory measurements were performed in the local hospitals where the visits were conducted. 1) Serum glucose: the oxidase method should be used; 2) HbAlc: it should be determined by high-performance liquid chromatography (HPLC); however, for those centers that could not follow this recommendation, the laboratory methods for HbA1c should obey the regional test rules.

\section{Quality Control of Data Collection and Study Monitoring}

The study was conducted in accordance with ICH guidelines and GCP standard. Investigators reported all data specified by the protocol by using a web-based electronic Case Report Form (CRF). A web-based study center was used to provide investigators $24 / 7$ support on conducting the study, frequent patient enrollment updates, study materials, and other informative material. Data quality control included the following steps: 1) automatic edit check at data entry on the EDC system; 2) real-time data query created by the EDC-attached data management system; 3) $100 \%$ site monitoring ensuring adequate patient enrollment, completion of original medical chart and documentation, and protocol compliance; 4) $50 \%$ remote source document verification (rSDV) and $10 \%$ onsite SDV at each site; 5) frequent data queries from a specific site would trigger a data audit visit at the site. Random site audits were also performed to ensure proper study conduct. Lab evaluations were completed at all sites before the enrolment starts. For data collection and quality control, all the data were recorded in the approved CRF and entered into a web-based electronic data capture system designed by Weishen Kangjian medical informatics company (Beijing, China).

\section{Statistical Analysis}

Descriptive statistics were used to characterize the data in the study, including calculations of means and standard deviations. The frequency and percentages (based on the non-missing sample size) of observed levels were reported for all categorical measures. The primary outcome was the overall proportion of patients reaching $\mathrm{HbA} 1 \mathrm{c}<7.0 \%$ at the end of six-month follow-up. Comparisons were statistically analyzed using one-way ANOVA and chi-squared tests. $\mathrm{P}$ value $<0.05$ for the two-tailed test was considered as statistically significant. Statistical analyses were conducted using SPSS version 22.0 (SPSS soft package, United States of America).

\section{Results}

\section{Baseline Characteristics}

Totally, 12,530 patients were included in this study. At baseline, the average age of these patients was 51.97 \pm 12.76 years, with $58 \%$ males. The average BMI was $24.46 \pm 3.83 \mathrm{~kg} / \mathrm{m}^{2}$, the average body weight was 67.89 $\pm 13.12 \mathrm{~kg}$, and the average $\mathrm{HbA} 1 \mathrm{c}$ was $8.33 \pm 2.11 \%$ with $24 \%$ of the patients achieving glycemic control target of $\mathrm{HbAl} 1 \mathrm{c}<7.0 \%$. Fasting glucose level was $8.00 \pm 2.65 \mathrm{mmol} / 1$ and postprandial glucose level was $9.70 \pm 3.42 \mathrm{mmol} / 1$. Details are shown in Table 1. 
Table I Glucose Control for All the Patients

\begin{tabular}{|c|c|}
\hline Variables & Mean \pm SD \\
\hline $\mathrm{HbAlc}(\%)$ & $8.33 \pm 2.11$ \\
\hline HbAlc at 3 months (\%) & $6.82 \pm 1.07$ \\
\hline HbAlc at 6 months (\%) & $6.75 \pm 0.94$ \\
\hline HbAlc change from baseline at 3 months (\%) & $-1.02 \pm 1.72$ \\
\hline HbAlc change from baseline at 6 months (\%) & $-1.01 \pm 1.67$ \\
\hline FPG (mmol/l) & $\begin{array}{l}8.00 \pm 2.65 \\
144 \pm 47.70(\mathrm{mg} / \mathrm{dl})\end{array}$ \\
\hline PPG (mmol/l) & $\begin{array}{l}9.70 \pm 3.42 \\
174.60 \pm 61.56(\mathrm{mg} / \mathrm{dl})\end{array}$ \\
\hline FPG change from baseline at I month ( $\mathrm{mmol} / \mathrm{l})$ & $\begin{array}{l}-0.97 \pm 2.96 \\
-17.46 \pm 53.28(\mathrm{mg} / \mathrm{dl})\end{array}$ \\
\hline PPG change from baseline at I month ( $\mathrm{mmol} / \mathrm{l})$ & $\begin{array}{l}-1.01 \pm 3.73 \\
-18.18 \pm 67.14(\mathrm{mg} / \mathrm{dl})\end{array}$ \\
\hline Proportion of patients reaching target $\mathrm{HbAlc}$ (\%) & $24 \%$ \\
\hline $\begin{array}{l}\text { Proportion of patients reaching target HbAlc } \\
\text { at } 3 \text { months (\%) }\end{array}$ & $59 \%$ \\
\hline $\begin{array}{l}\text { Proportion of patients reaching target } \mathrm{HbAlc} \\
\text { at } 6 \text { months (\%) }\end{array}$ & $67 \%$ \\
\hline Insulin dosage at baseline (U/kg) & $0.23 \pm 0.09$ \\
\hline Insulin dosage at endpoint (U/kg) & $0.23 \pm 0.23$ \\
\hline
\end{tabular}

Note: Values are expressed as mean \pm standard deviation.

Abbreviations: FPG, fasting plasma glucose; SD, standard deviation.

\section{Glycemic Control $\mathrm{HbAlc}$}

After 3 months of follow-up, the average HbA1c change from baseline was $-1.02 \pm 1.72 \%$, with $59 \%$ of the patients reaching $\mathrm{HbAlc}$ target. After 6 months of follow-up, the average $\mathrm{HbA} 1 \mathrm{c}$ change from baseline was $-1.01 \pm 1.67 \%$, with $66 \%$ of the patients reaching $\mathrm{HbAlc}$ target. Compared with baseline levels, the levels of $\mathrm{HbAlc}$ at 3 months and 6 months decreased significantly $(\mathrm{p}<0.01)$ and the proportions of participants achieving $\mathrm{HbA} 1 \mathrm{c}$ target at 3 months and 6 months improved significantly $(p<0.01)$.

Differences in HbAlc changes and the percentage of patients achieving treatment target by patient age and BMI were summarized in Figures 2 and 3. Compared with elderly patients, younger patients achieved more reduction in $\mathrm{HbAlc}$ changes but with lower percentage of patients reaching the treatment target of $\mathrm{HbAlc}<7 \%$. Compared with patients with normal weight, both obese patients and thinner patients tended to get more decreases in $\mathrm{HbAlc}$ changes but with similar percentage of patients reaching the target of HbAlc. When stratified by regions, baseline HbA1c levels of patients were lowest in northeast region while highest in southeast region. HbA1c levels decreased most from baseline at six months were in the southwest region while $\mathrm{HbA1c}$ levels decreased lest at six months were in the southeast region. $\mathrm{HbAlc}$ levels at baseline or at 3 months or 6 months were significantly different among different regions (Figure 4).

\section{FPG and PPG}

After 3 months of follow-up, the average FPG change from baseline was $-1.02 \pm 1.72 \%$. After 1 month, 3 months, 6 months treatment with basal insulin as well as educated by the APP, the average FPG level was $7.03 \pm 1.85 \mathrm{mmol} / \mathrm{l}(126.54$ $\pm 33.30 \mathrm{mg} / \mathrm{dl}), 7.00 \pm 1.83 \mathrm{mmol} / \mathrm{l}(126.00 \pm 32.94 \mathrm{mg} / \mathrm{dl})$, and $7.10 \pm 1.98 \mathrm{mmol} / \mathrm{l}(127.80 \pm 35.64 \mathrm{mg} / \mathrm{dl})$ respectively, and the average PPG level was $8.94 \pm 2.83 \mathrm{mmol} / \mathrm{l}(160.92 \pm 50.94 \mathrm{mg} /$ dl), $8.63 \pm 2.56 \mathrm{mmol} / \mathrm{l}(155.34 \pm 46.08 \mathrm{mg} / \mathrm{dl})$ and $8.52 \pm 2.53$ $\mathrm{mmol} / \mathrm{l}(153.36 \pm 45.54 \mathrm{mg} / \mathrm{dl})$, respectively.

\section{Insulin Dosage}

At baseline, the average insulin dosage was $0.23 \pm 0.09 \mathrm{IU} / \mathrm{kg}$. After 6 months of treatment and education, the final average insulin dosage was $0.23 \pm 0.23 \mathrm{IU} / \mathrm{kg}$, which was not significantly different from the dosage from baseline.

Differences of insulin dosages at baseline and after 6-month of treatment stratified by patient age were also summarized, but no significance was found. When stratified by baseline BMI, insulin dosage of patients in the group of $\mathrm{BMI}<19 \mathrm{~kg} / \mathrm{m}^{2}$ was $0.29 \pm 0.13 \mathrm{IU} / \mathrm{kg}$ at baseline and 0.28 $\pm 0.13 \mathrm{IU} / \mathrm{kg}$ finally, insulin dosage in individuals with a BMI $19-24.99 \mathrm{~kg} / \mathrm{m}^{2}$ was $0.24 \pm 0.10 \mathrm{IU} / \mathrm{kg}$ at baseline and $0.24 \pm 0.10 \mathrm{IU} / \mathrm{kg}$ finally. In individuals with a BMI $24-27.99 \mathrm{~kg} / \mathrm{m}^{2}$, insulin dosage was $0.22 \pm 0.08 \mathrm{IU} / \mathrm{kg}$ at baseline and did not change after 6-month treatment. In individuals with a BMI $28-31.99 \mathrm{~kg} / \mathrm{m}^{2}$, and in patients with $\mathrm{BMI} \geq 32 \mathrm{~kg} / \mathrm{m}^{2}$, insulin dosage was $0.20 \pm 0.08 \mathrm{IU} / \mathrm{kg}$ and $0.16 \pm 0.08 \mathrm{IU} / \mathrm{kg}$ at baseline, respectively, without significant change after 6-month treatment (Figure 5). Insulin dosages at baseline and at the endpoint among different regions did not show any significant difference (Figure 5).

\section{OADs in Combination with Basal Insulin}

In the data of oral drug use, there were 3145 patients in the basic insulin combined with one oral drug treatment group, 1204 in the combined two oral drug treatment group, 208 in the combined three oral drug treatment group and 17 in the combined four oral drug treatment group.

For patients with only one OAD in combination with basal insulin, the first four kinds of OADs were metformin 


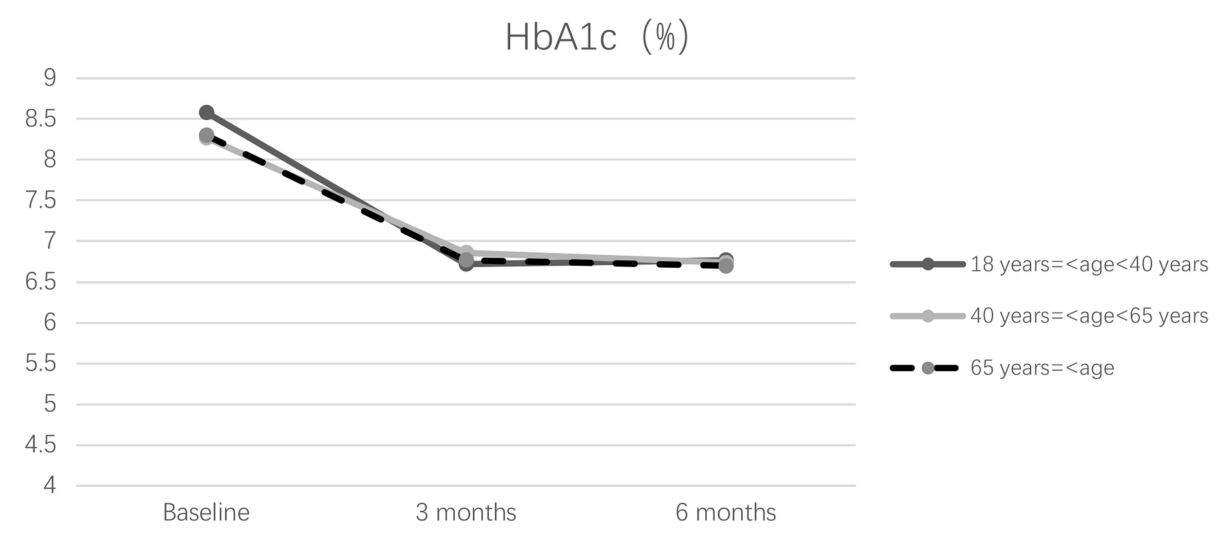

2A

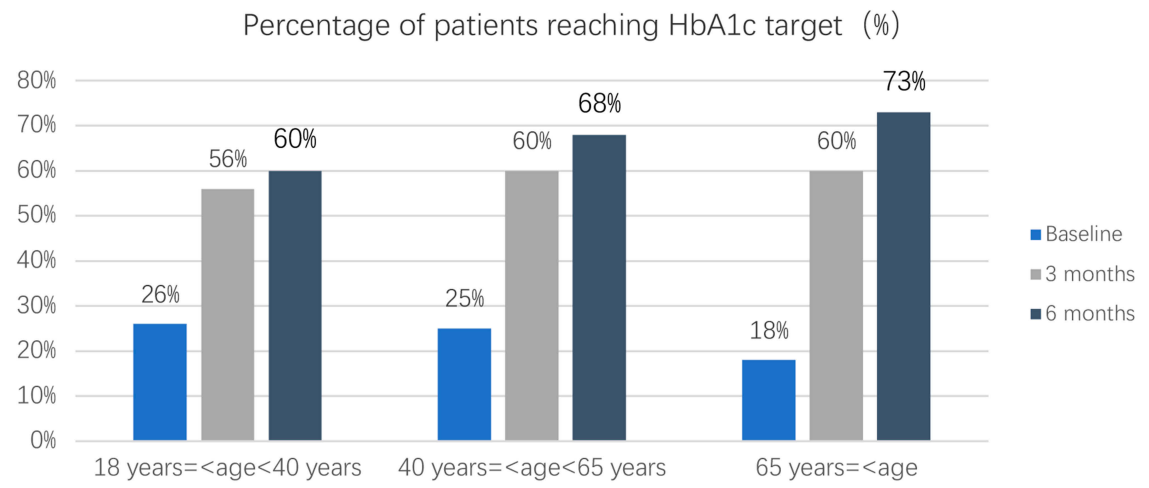

2B

HbA1c change from baseline (\%)

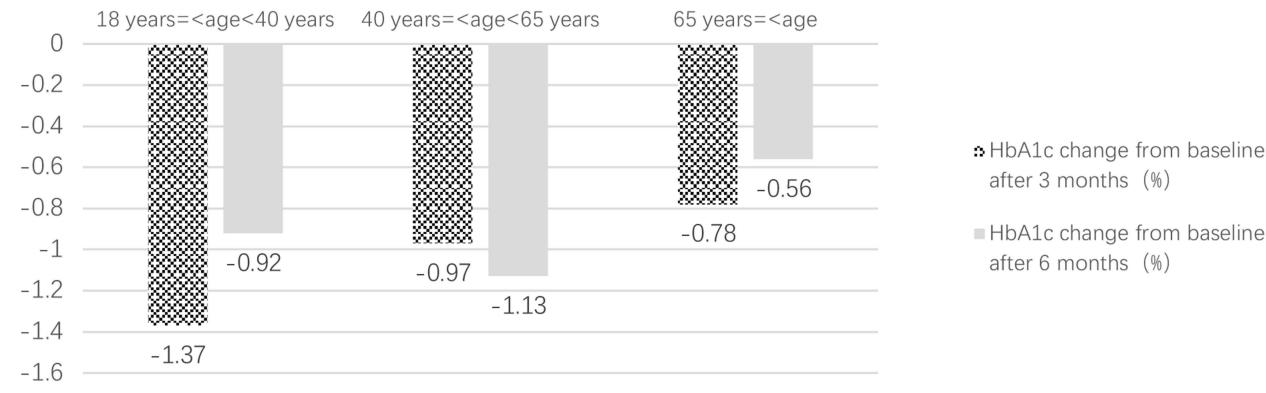

$2 \mathrm{C}$

Figure 2 Glucose control stratified by age. (A) HbAlc level stratified by age; (B) Percentage of patients reaching $\mathrm{HbAlc}$ target stratified by age; (C) $\mathrm{HbAlc}$ change from baseline stratified by age.

(56.4\%), a-glucosidase inhibitors (32.9\%), sulfonylureas (7.4\%) and DPP-4 inhibitors (0.4\%). For patients with two OADs in combination with basal insulin, the first four combination therapies of OADs were metformin plus a-glucosidase inhibitors (52.2\%), metformin plus sulfonylureas (20.8\%), metformin plus DPP-4 inhibitors (9.8\%) and sulfonylureas plus a-glucosidase inhibitors $(8.8 \%)$.
The proportion of males in the group treated with basic insulin combined with one, two, three and four oral drugs was $59 \%, 61 \%, 67 \%$ and $65 \%$, respectively. The age of the group treated with basic insulin combined with one, two, three and four oral medications was $51.82(+12.63), 52.35$ $(+11.96), 52.97(+11.99)$ and $53.06(+8.74)$, respectively. BMI was $24.54\left(+3.71 \mathrm{~kg} / \mathrm{m}^{2}\right), 24.98\left(+3.86 \mathrm{~kg} / \mathrm{m}^{2}\right), 25.38$ 


\section{$\operatorname{HbA1c}(\%)$}

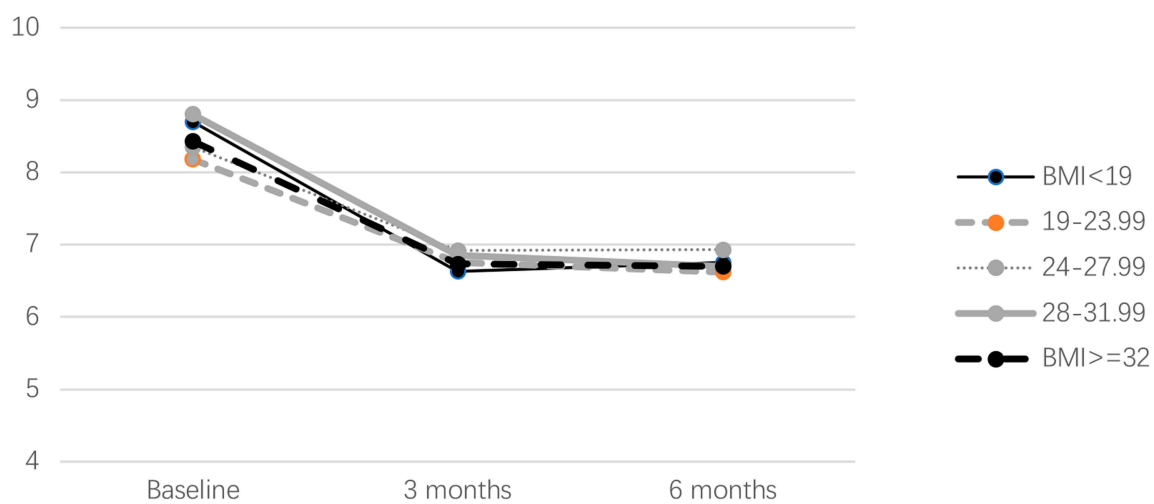

$3 \mathrm{~A}$

HbA1c change from baseline (\%)

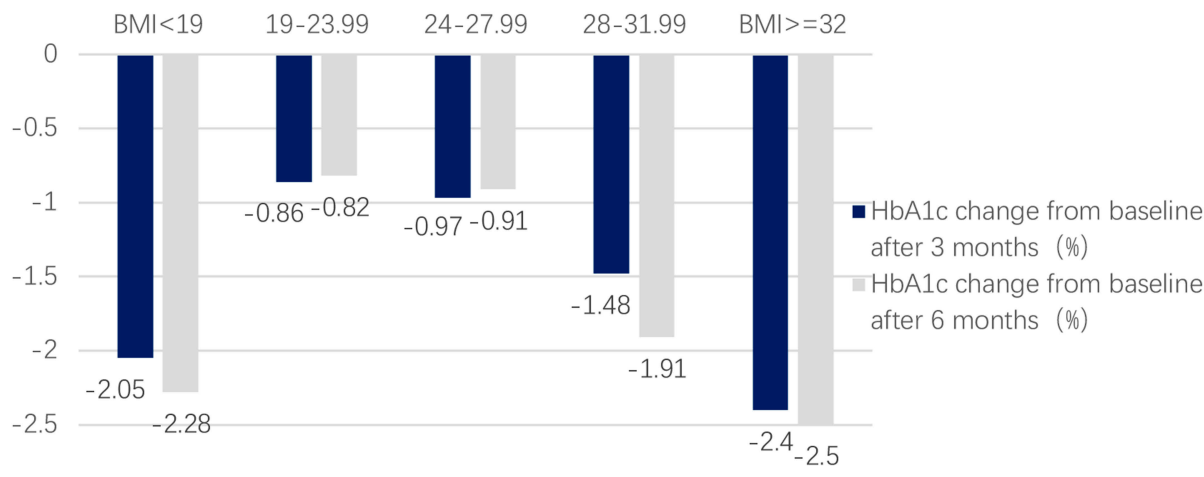

3B

Percentange of patients reaching $\mathrm{HbA} 1 \mathrm{c}$ target (\%)

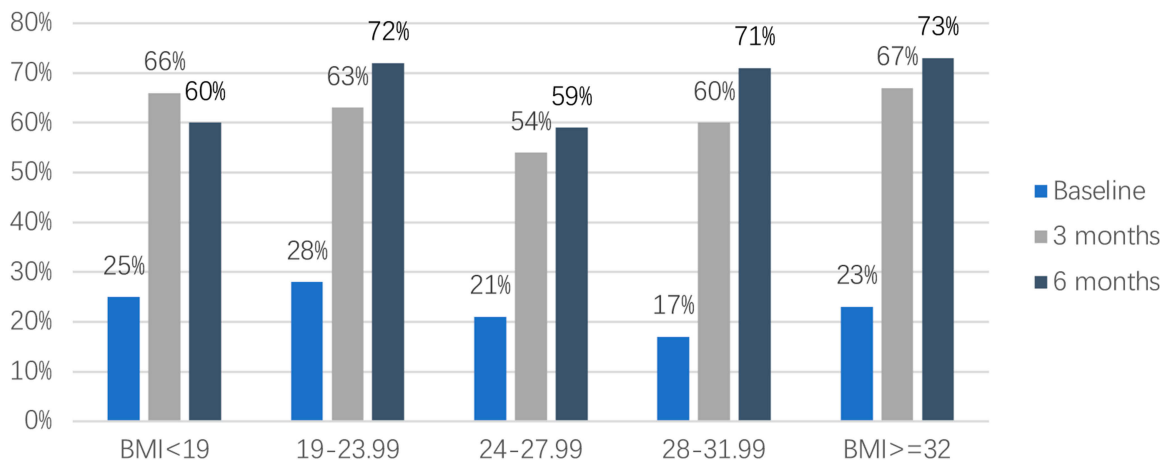

$3 \mathrm{C}$

Figure 3 Glucose control stratified by BMI. (A) HbAlc level stratified by BMI; (B) HbAlc change from baseline stratified by BMI; (C) Percentage of patients reaching HbAIc target stratified by BMI.

$\left(+3.40 \mathrm{~kg} / \mathrm{m}^{2}\right)$ and $25.87\left(+2.76 \mathrm{~kg} / \mathrm{m}^{2}\right)$ in the group treated with basic insulin combined with one, two, three and four oral drugs.
The baseline glycosylated hemoglobin in the group treated with basic insulin combined with one, two, three or four oral drugs was $8.27(+1.96 \%), 8.90$ 


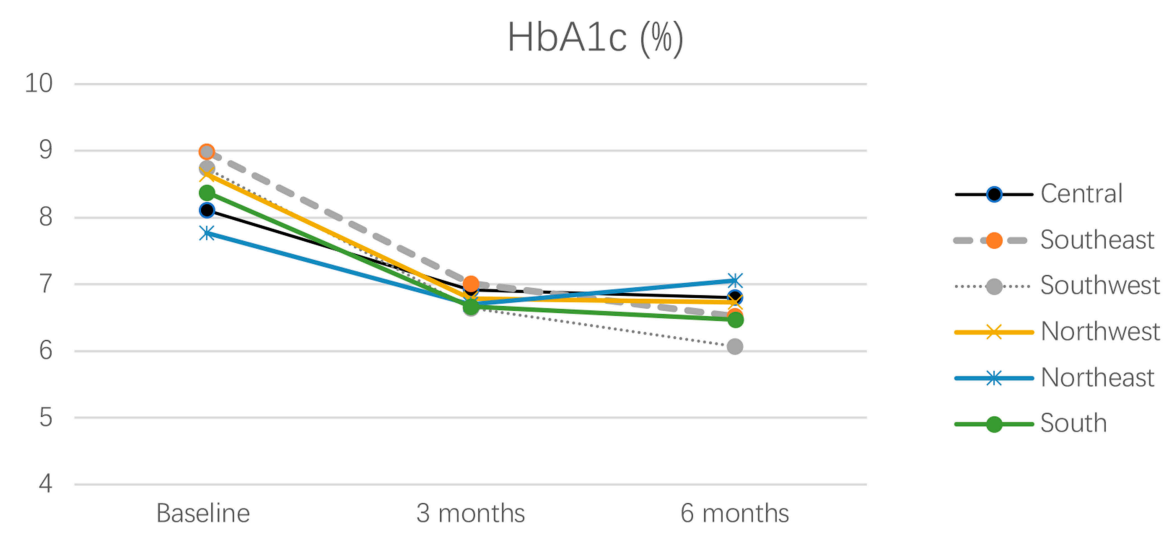

$4 \mathrm{~A}$

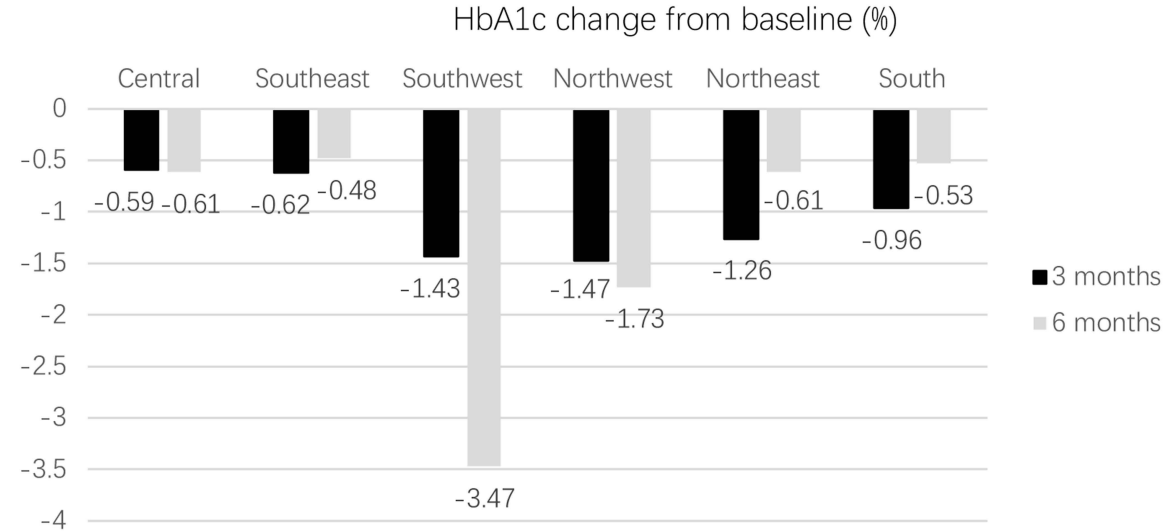

$4 B$

Percentange of patients reaching $\mathrm{HbA} 1 \mathrm{c}$ target (\%)

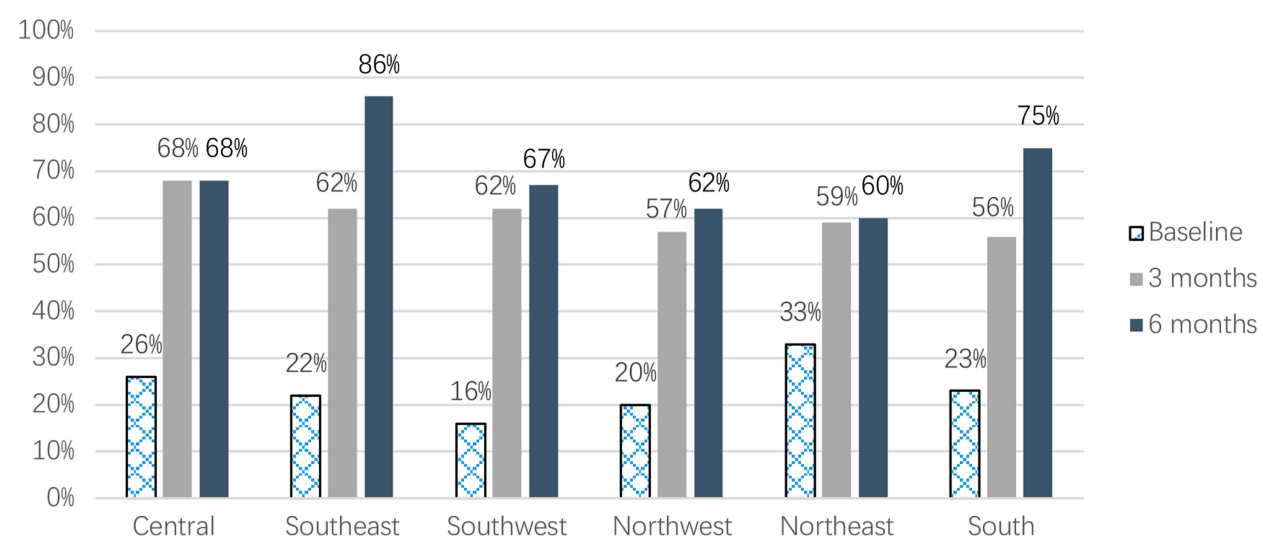

$4 \mathrm{C}$

Figure 4 Glucose control stratified by regions. (A) HbAlc level stratified by regions; (B) HbAlc change from baseline stratified by regions; (C) Percentage of patients reaching $\mathrm{HbAlc}$ target stratified by regions.

$(+2.10 \%), 8.84(+2.19 \%)$ and $9.03(+1.72 \%)$. The baseline glycosylation rates of patients treated with basic insulin combined with one, two, three or four oral drugs were $21 \%, 14 \%, 15 \%$ and $8 \%$. The threemonth glycosylation changes in the group treated with basic insulin combined with one, two, three or 
Insulin dosage (IU/KG)

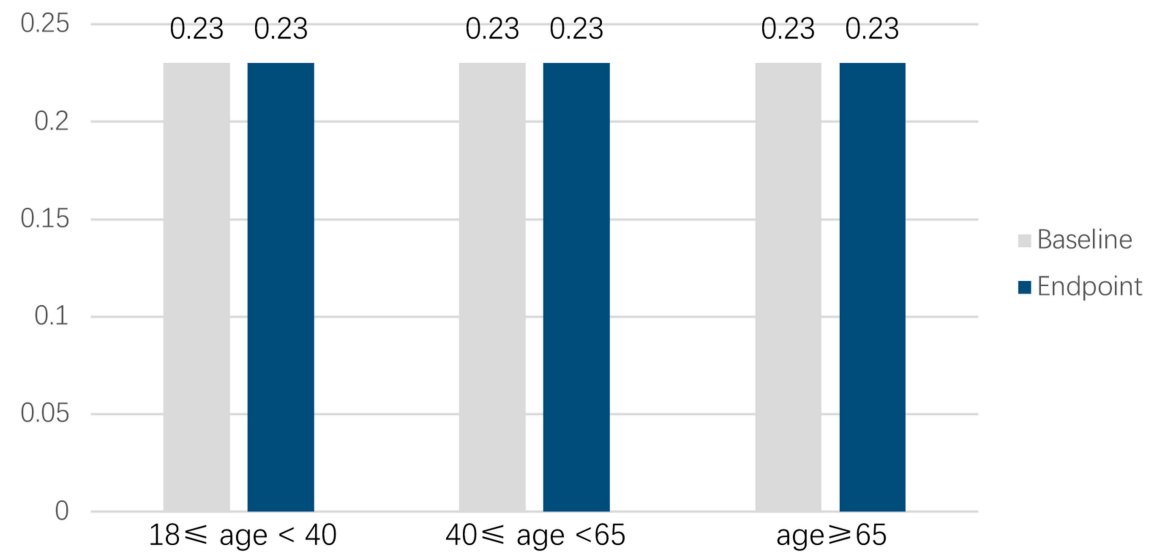

$5 \mathrm{~A}$

Insulin dosage (IU/KG)

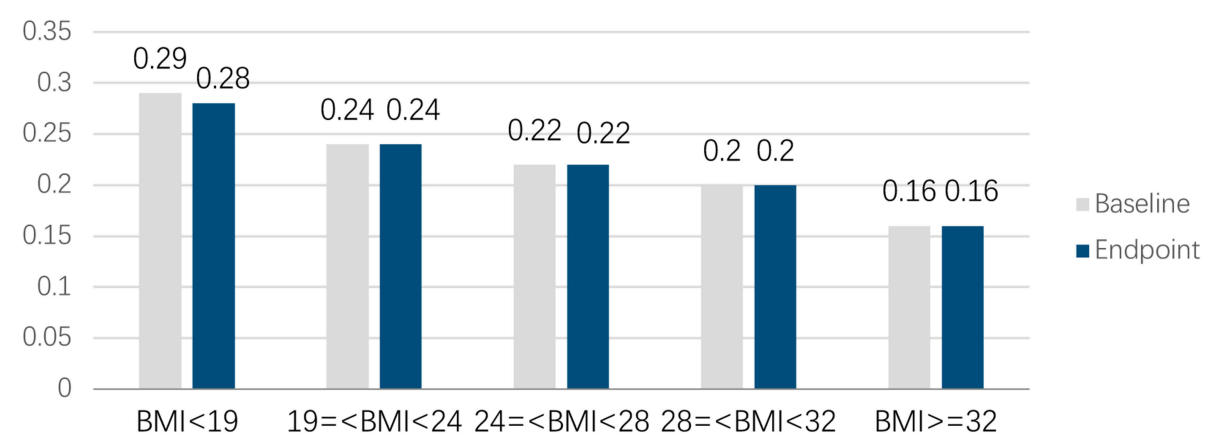

$5 B$

Insulin dosage ( IU/KG)

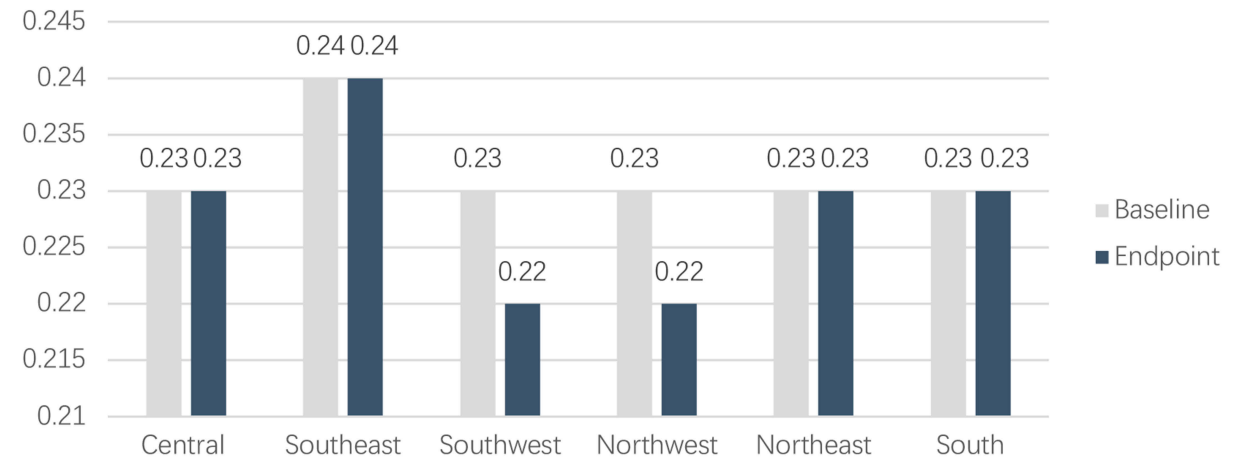

$5 \mathrm{C}$

Figure 5 Insulin dosage at baseline and endpoint. (A) Insulin dosage at baseline and endpoint stratified by age. Figure (B) Insulin dosage at baseline and endpoint stratified by BMI. (C) Insulin dosage at baseline and endpoint stratified by regions.

four oral drugs were $-1.19(-1.85 \%),-1.19(-1.74 \%)$, insulin combined with one, two and three oral $-0.52(-0.81 \%),-2.30(-4.24 \%)$. The six-month gly- medications were $-1.11(-1.91 \%),-1.40(-1.62 \%)$, cosylation changes of the patients treated with basic $-0.88(-1.29 \%)$. 
The baseline insulin dose per unit body weight was $0.23(+0.10 \mathrm{U} / \mathrm{kg}), 0.23(+0.09 \mathrm{U} / \mathrm{kg}), 0.23(+0.09 \mathrm{U} / \mathrm{kg})$ and $0.22(+0.01 \mathrm{U} / \mathrm{kg})$ in the group of baseline insulin combined with one, two, three and four oral medications. The baseline insulin doses in the group treated with basic insulin combined with one, two, three or four oral drugs were $15.25(+6.09 u), 15.86(+6.01 u), 16.08(+5.91 u)$ and $15.29(+4.34 \mathrm{u})$. The end-point insulin dose per unit weight was $0.23(+0.10 \mathrm{U} / \mathrm{kg}), 0.23(+0.09 \mathrm{U} / \mathrm{kg}), 0.23(+0.09 \mathrm{U} /$ $\mathrm{kg}), 0.23(+0.09 \mathrm{U} / \mathrm{kg})$ and $0.23(+0.11 \mathrm{U} / \mathrm{kg})$. The endpoint insulin doses in the group treated with basic insulin combined with one, two, three or four oral drugs were $15.15(+6.21 u), 15.58(+6.01 u), 16.01(+6.01 u)$ and 16.00 $(+7.71 \mathrm{u})$. Details are shown in Table 2.

\section{Discussion}

The results of the basic insulin optimal management project showed that the average $\mathrm{HbAlc}$ at the beginning of basic insulin therapy was $8.33 \%$. Previous ORBIT study has shown that the average $\mathrm{HbA} 1 \mathrm{c}$ level of onset insulin therapy in T2D in China was 9.6\%. ${ }^{11-13}$ However, this does not meet the recommendation of the Chinese guidelines for the prevention and treatment of T2D that patients with HBA1c levels above $7 \%$ of the oral medicines that do not meet the standard should start insulin therapy, ${ }^{14}$ which suggested that the current situation of using basic insulin in clinic is late and clinical inertia exists. Therefore, the timing of initial treatment of basic insulin is particularly important. The level of HbAlc in the initial insulin therapy of the basic insulin optimization management project was significantly lower than that of the previous studies, which reflected the improvement of the starting time of basic insulin in China to a certain extent.

The results of baseline insulin optimal management project showed that the baseline insulin dose was 0.23 $(+0.09 \mathrm{U} / \mathrm{kg})$ and the end-point insulin dose was 0.23 $(+0.23 \mathrm{U} / \mathrm{kg})$. Previous ORBIT study showed that the initial dose of insulin was low with $0.18 \mathrm{U} / \mathrm{kg}$. After initial basal insulin treatment, about $40 \%$ of the patients did not adjust insulin dosage in the past three months. At the sixth month follow-up, the basal insulin dosage was only $0.21 \mathrm{U} / \mathrm{kg}$, which was only $0.03 \mathrm{U} / \mathrm{kg} / \mathrm{d}$ higher than the baseline insulin dosage. ${ }^{12}$ In this basic insulin optimization management project, the initial basal insulin dose was relatively higher

Table 2 Clinical Characteristics in Different OAD Groups

\begin{tabular}{|c|c|c|c|c|c|}
\hline Parameters & I OAD & 2 OADs & 3 OADs & 4 OADs & $P$ value \\
\hline $\mathbf{n}$ & 3145 & 1204 & 208 & 17 & \\
\hline Gender (male percent) & $59 \%$ & $61 \%$ & $67 \%$ & $65 \%$ & 0.059 \\
\hline Age (year) & $51.82 \pm 12.63$ & $52.35 \pm 11.96$ & $52.97 \pm 11.99$ & $53.06 \pm 8.74$ & 0.410 \\
\hline Body weight (kg) & $68.03 \pm 12.60$ & $69.71 \pm 13.45$ & $71.93 \pm 12.66$ & $72.06 \pm 10.96$ & 0.000 \\
\hline $\mathrm{BMI}\left(\mathrm{kg} / \mathrm{m}^{2}\right)$ & $24.54 \pm 3.71$ & $24.98 \pm 3.86$ & $25.38 \pm 3.40$ & $25.87 \pm 2.76$ & 0.000 \\
\hline Insulin dosage per weight at baseline $(\mathrm{U} / \mathrm{kg})$ & $0.23 \pm 0.10$ & $0.23 \pm 0.09$ & $0.23 \pm 0.09$ & $0.22 \pm 0.01$ & 0.776 \\
\hline Insulin dosage at baseline $(\mathrm{u})$ & $15.25 \pm 6.09$ & $|5.86 \pm 6.0|$ & $|6.08 \pm 5.9|$ & $15.29 \pm 4.34$ & 0.010 \\
\hline Insulin dosage per weight at endpoint $(\mathrm{U} / \mathrm{kg})$ & $0.23 \pm 0.10$ & $0.23 \pm 0.09$ & $0.23 \pm 0.09$ & $0.23 \pm 0.11$ & 0.998 \\
\hline Insulin dosage at endpoint $(\mathrm{u})$ & $15.15 \pm 6.21$ & $|5.58 \pm 6.0|$ & $16.01 \pm 6.01$ & $|6.00 \pm 7.7|$ & 0.064 \\
\hline $\mathrm{HbAlc}$ at baseline (\%) & $8.27 \pm 1.96$ & $8.90 \pm 2.10$ & $8.84 \pm 2.19$ & $9.03 \pm 1.72$ & 0.000 \\
\hline Proportion of patients reaching target & $21 \%$ & $14 \%$ & $15 \%$ & $8 \%$ & 0.000 \\
\hline $\mathrm{HbAlc}$ change from baseline at 3 months (\%) & $-1.19 \pm 1.85$ & $-1.19 \pm 1.74$ & $-0.52 \pm 0.81$ & $-2.30 \pm 4.24$ & 0.203 \\
\hline $\mathrm{HbAlc}$ change from baseline at 6 months (\%) & $-1.11 \pm 1.91$ & $-1.40 \pm 1.62$ & $-0.88 \pm 1.29$ & 1 & 0.618 \\
\hline FPG at baseline $(\mathrm{mmol} / \mathrm{l})$ & $8.06 \pm 2.64$ & $8.13 \pm 2.87$ & $8.03 \pm 3.00$ & $9.36 \pm 2.96$ & 0.243 \\
\hline PPG at baseline $(\mathrm{mmol} / \mathrm{l})$ & $9.88 \pm 3.48$ & $9.66 \pm 3.33$ & $9.38 \pm 3.13$ & $9.34 \pm 2.39$ & 0.251 \\
\hline FPG at I month $(\mathrm{mmol} / \mathrm{l})$ & $7.05 \pm 1.94$ & $7.00 \pm 1.56$ & $7.07 \pm 2.10$ & $7.97 \pm 1.77$ & 0.245 \\
\hline FPG change from baseline at I month ( $\mathrm{mmol} / \mathrm{l})$ & $-0.99 \pm 2.95$ & $-1.11 \pm 2.91$ & $-0.92 \pm 2.98$ & $-1.40 \pm 3.97$ & 0.716 \\
\hline PPG at I month $(\mathrm{mmol} / \mathrm{l})$ & $9.09 \pm 2.85$ & $9.00 \pm 2.67$ & $8.51 \pm 2.19$ & 5.90 & 0.428 \\
\hline PPG change from baseline at I month $(\mathrm{mmol} / \mathrm{l})$ & $-1.08 \pm 3.87$ & $-1.08 \pm 3.52$ & $-0.60 \pm 3.23$ & -1.10 & 0.953 \\
\hline FPG at 3 months $(\mathrm{mmol} / \mathrm{l})$ & $7.02 \pm 1.83$ & $6.99 \pm 1.82$ & $7.03 \pm 2.09$ & $7.13 \pm 1.10$ & 0.987 \\
\hline PPG at 3 months $(\mathrm{mmol} / \mathrm{l})$ & $8.79 \pm 2.64$ & $8.48 \pm 2.62$ & $9.03 \pm 3.36$ & $7.60 \pm 0.84$ & 0.341 \\
\hline FPG at 6 months $(\mathrm{mmol} / \mathrm{l})$ & $7.02 \pm 1.90$ & $7.10 \pm 1.87$ & $6.87 \pm 1.55$ & $6.35 \pm 0.35$ & 0.821 \\
\hline PPG at 6 months $(\mathrm{mmol} / \mathrm{l})$ & $8.49 \pm 2.57$ & $8.55 \pm 2.38$ & $7.57 \pm 2.00$ & 1 & 0.239 \\
\hline
\end{tabular}

Note: Values are expressed as number (percentage) or mean \pm standard deviation.

Abbreviations: BMI, body mass index; FPG, fasting plasma glucose; PPG, postprandial plasma glucose; OAD, oral anti-diabetic drug; SD, standard deviation. 
than that in the ORBIT study, and the HbA1c compliance rate was $59 \%$ after 3 months. It can be seen from this that starting as early as possible and starting at a higher dose can effectively improve glucose control of patients and improve the rate of patients reaching the target.

The basic insulin optimization management project, by using Internet and mobile phone APP, created a platform for doctors and patients to communicate and educate them about insulin therapy and self-management for up to six months. This not only enables diabetics who first use basic insulin to record their injection behavior, learn to monitor blood sugar and understand the changes of their condition, but also alleviates the anxiety and resistance of those who first use insulin. In addition, the initial insulin treatment of diabetic patients in the initial stage of insulin injection will also have many irregular use problems, which will affect the clinical efficacy of patients receiving insulin treatment. The basic insulin optimization management project can help patients to monitor and manage their blood sugar. When patients encounter injection problems or blood sugar control problems, they can turn to doctors through the APP system, which can soothe patients' panic, and also improve patients' awareness of the importance of regular monitoring of blood sugar. To help patients meet safety standards, it can also reduce the increased visits of patients due to injection problems or panic or other unnecessary medical treatment.

With the continuous development of society, the living standard of Chinese people is constantly improving, and the quality of life is rising step by step. However, the symbolic problem brought by modern lifestyle is the increase of people's weight and the decrease of activity, and the intake of nutrients is too delicate and excessive, which leads to more and more diabetic patients. Faced with such a severe situation, medical workers have a long way to go. While providing standardized diagnosis and treatment for patients, it is also necessary for our endocrinologist and diabetologist to educate patients about diabetes. As a center, patients need to cooperate with doctors in self-management, so that they can complement each other. In recent years, the rapid development of the Internet in China has provided a platform for doctors and patients. It is on this platform that the basic insulin optimization management project assists doctors, benefits patients and develops a new model for diabetes treatment.

Although this study is a study to achieve optimal management of initiating basal insulin treatment in type 2 diabetes patients in China, we shall admit that compared to oral hypoglycemic treatments, insulin treatment has several disadvantages, such as that insulin is more expensive, has higher nonadherence rates and worse hypoglycemia events. Nonadherence has been associated with higher distress from frequent needle sticks, increasing costs of insulin, poor health literacy, fear of hypoglycemia, changing eating patterns, and dose confusion. Therefore, it is unfortunate to give these individuals a life-long medication when other likely would have been as or more efficacious, lower cost, and promoted a better quality of life. So it is quite important to maximize oral medications prior to starting insulin for individuals.

There is really the need to educate providers on that initiating insulin treatment after maximized on oral agents, in order not to prematurely place patients on insulin for all the reasons stated above. Future studies using this technology to titrate oral medications to their maximum doses would be valuable and likely cost saving to the patient and health system compared to insulin. Future studies for this technology and T1D would also be valuable. However, for those who need insulin, data from this study is a valuable resource, potentially reducing the risk of DM sequelae. What is more, results from achieving optimal diabetes management in basal insulin used patients by using mobile health APP might be expanded to oral hypoglycemics or to other diseases that require frequent titration, such as hypertension, would be valuable to multiple populations, particularly resource-poor countries with minimal access to healthcare providers.

As an observational study, there are some limitations for this study. Firstly, although the HPLC was recommended for $\mathrm{HbA} 1 \mathrm{c}$ testing, some primary clinics could not follow this recommendation in China. And no further correction was done for the value of HbAlc in this study. Therefore, the inconsistency of the laboratory methods for HbAlc was one of the limitations of this study. However, taking realworld evidence and study cost into consideration, we accepted the results of lab test from variable hospitals. And fortunately, in recent years, a series of industry standards have been implemented; thus, the reference difference among individual labs becomes small. Secondly, as an observational study for evaluating the effective and efficient basal insulin optimal management by using mobile health application (APP) for T2D patients in China, this duration with 6 months of follow-up is not enough to give us comprehensive answers. Thirdly, the influence of more factors such as educational levels, socio-economic demographics, or eating habits, etc. were not collected in this study. Thus, 
a multiple-year longitudinal cohort study will be further needed. Fourthly, the HbAlc target for older patients is still controversial. However, as this study is an observational cohort study, a real-world study in China, as the recommendation from the Chinese Guideline for Diabetes Prevention and Treatment did not set the HbAlc target for older patients, we did not stratify the target of glucose control for different ages in this study. Moreover, unfortunately, we could not get the endpoint body weight or BMI from the data for that the majority of participants did not report their body weight at 6 months, which is also a limitation of this study. However, the average baseline BMI reported from this study was similar to that reported in the ORBIT study, which is a real-world observational study evaluating basal insulin use in Chinese T2D patients. Therefore, we shall interpret this study with caution.

\section{Conclusion}

In the face of the growing number of diabetic patients who need insulin treatment, propaganda and education of the importance of self-blood sugar management for diabetic patients, and the Internet APP model is a form of effective self-management that help patients greatly. Moreover, the basic insulin optimization management project also confirms that for patients with T2D who fail to meet the oral drug treatment standard, starting the basic insulin as early as possible and starting the appropriate dose of basic insulin can effectively improve blood sugar and help patients reach the glucose control target as soon as possible.

\section{Ethics and Consent Statement}

The protocol of this program was approved by the Ethical Committee of Peking University International Hospital. At every participating hospital, the aim of the study was clearly explained to each study participant and then, informed consent was obtained voluntarily from each study subject before any data collection. The study was conducted in accordance with the Declaration of Helsinki.

\section{Acknowledgment}

Authors of this manuscript would like to thank all study investigators in the participated hospitals (see the Supplemental Table S1 for a complete list of hospitals and investigators) for their contribution to the successful completion of this study.

\section{Author Contributions}

All authors made substantial contributions to conception and design, acquisition of data, or analysis and interpretation of data; took part in drafting the article or revising it critically for important intellectual content; gave final approval of the version to be published; and agree to be accountable for all aspects of the work.

\section{Funding}

This study was supported by Ganli Ltd. (China) company. The funding agencies had no role in the study design, data collection or analysis, decision to publish or preparation of the manuscript.

\section{Disclosure}

Linong Ji has received fees for lecture presentations from AstraZeneca, Merck, Novartis, Lilly, Roche, Sanofi-Aventis and Takeda. Linong Ji has received consulting fees from companies including AstraZeneca, Merck, Novartis, Lilly, Roche, Sanofi-Aventis and Takeda. Linong Ji has received grants/research support from AstraZeneca, Bristol-Myers Squibb, Ganli, Merck, Novartis, and Sanofi-Aventis. The authors report no other conflicts of interest in this work.

\section{References}

1. Xu Y, Wang L, He J, et al. Prevalence and control of diabetes in Chinese adults. JAMA. 2013;310(9):948-959. doi:10.1001/jama.2013.168118

2. Wang L, Gao P, Zhang M, et al. Prevalence and ethnic pattern of diabetes and prediabetes in China in 2013. JAMA. 2017;317 (24):2515-2523. doi:10.1001/jama.2017.7596

3. International Diabetes Federation. IDF Diabetes Atlas, 8th edition. [cited January 10, 2018] 2017; Available from: https:/www.idf.org/e-library/ epidemiology-research/diabetes-atlas.html. Accessed April 16, 2020.

4. Nour M, Chen J, Allman-Farinelli M. Efficacy and external validity of electronic and mobile phone-based interventions promoting vegetable intake in young adults: systematic review and meta-analysis. J Med Internet Res. 2016;18:e58. doi:10.2196/ jmir.5082

5. Hall AK, Cole-Lewis H, Bernhardt JM. Mobile text messaging for health: a systematic review of reviews. Annu Rev Public Health. 2015;36:393-415. doi:10.1146/annurev-publhealth-031914-122855

6. Devi BR, Syed-Abdul S, Kumar. A. mHealth: an updated systematic review with a focus on HIV/AIDS and tuberculosis long term management using mobile phones. Comput Methods Programs Biomed. 2015;122:257-265. doi:10.1016/j.cmpb.2015.08.003

7. Cui M, Wu X, Mao J. T2DM self-management via smartphone applications: a systematic review and meta-analysis. PLoS One. 2016;11: e0166718. doi:10.1371/journal.pone.0166718

8. Carallo C, Scavelli FB, Cipolla M. Management of type 2 diabetes mellitus through telemedicine. PLoS One. 2015;10:e126858. doi:10.1371/journal.pone. 0126858

9. Mulvaney SA, Ritterband LM, Bosslet L. Mobile intervention design in diabetes: review and recommendations. Curr Diab Rep. 2011;11:486-493. doi:10.1007/s11892-011-0230-y 
10. Pal K, Eastwood SV, Michie S. Computer-based interventions to improve self-management in adults with type 2 diabetes: a systematic review and meta-analysis. Diabetes Care. 2014;37 (6): $1759-1766$. doi: $10.2337 / \mathrm{dc} 13-1386$

11. Ji L, Zhang P, Zhu D, et al.; ORBIT study group. Comparative effectiveness and safety of different basal insulins in a real-world setting. Diabetes Obes Metab. 2017;19(8):1116-1126. doi:10.1111/dom.12920

12. Ji L, Zhang P, Zhu D, et al. Observational Registry of Basal Insulin Treatment (ORBIT) in patients with type 2 diabetes uncontrolled with oral antihyperglycaemic drugs: real-life use of basal insulin in China. Diabetes Obes Metab. 2017;19(6):822-830. doi:10.1111/dom.12886
13. Ji L, Zhang P, Weng J, et al. Observational Registry of Basal Insulin Treatment (ORBIT) in Patients with Type 2 diabetes uncontrolled by oral hypoglycemic agents in China-study design and baseline characteristics. Diabetes Technol Ther. 2015;17(10):735-744. doi:10.1089/ dia.2015.0054

14. Weng J, Ji L, Jia W, et al.; Chinese Diabetes Society. Standards of care for type 2 diabetes in China. Diabetes Metab Res Rev. 2016;32 (5):442-458. doi:10.1002/dmrr.2827.

\section{Publish your work in this journal}

Diabetes, Metabolic Syndrome and Obesity: Targets and Therapy is an international, peer-reviewed open-access journal committed to the rapid publication of the latest laboratory and clinical findings in the fields of diabetes, metabolic syndrome and obesity research. Original research, review, case reports, hypothesis formation, expert opinion and commentaries are all considered for publication. The manuscript management system is completely online and includes a very quick and fair peer-review system, which is all easy to use. Visit http://www.dovepress.com/testimonials.php to read real quotes from published authors. 